\title{
Assessment of Nurses' Knowledge and Practice Regarding Patients with Postextubation Dysphagia in Trauma Intensive Care Unit
}

\author{
Mohammed Mahyoub Ahmed ${ }^{1}$, Mona Ali Mohammed ${ }^{2}$ \& Mervat Anwar AbdEl-Aziz $^{3}$. \\ ${ }^{1 .}$ Demonstrator in Nursing Department, Thamar University, Yemen. \\ 2. Assistant professor, Critical Care nursing Department, Faculty of Nursing, Assiut University, Egypt. \\ ${ }^{3 .}$ Assistant professor, Critical Care nursing Department, Faculty of Nursing, Assiut University, Assiut, Egypt.
}

\begin{abstract}
Nearly $60 \%$ of patients who are intubated in intensive care units (ICUs) experience dysphagia after extubation, and approximately $50 \%$ of them aspirate. Little is known about dysphagia recovery time after patients are discharged from the hospital. Aim of the study was to assessment of nurses' knowledge and practice regarding patients with postextubation dysphagia in trauma intensive care unit. Subjects and methods: Descriptive design was utilized in this study on a convenient sample of 50 nurses'. The study was conducted in the trauma intensive care unit. Data was collected using a self-administered questionnaire with closed-ended questions which was developed by the researcher. The assessment was performed by using a questionnaire for knowledge and check list for practice assessment. Results: The study found that $40.0 \%$ of nurses' were more 30 years. Regarding to educational qualifications, more than $50 \%$ of nurses' had diploma nursing. The findings of study show that nurses have low overall knowledge and practice level. In conclusion: the overall knowledge of participants was found to be low knowledge about postextubation dysphagia. Regarding the overall practice of nurses' was found to be low practice. Recommendations: Nurses in need for in-service training programs and refreshing courses to improve their knowledge, which will reflect into their practice while working with patients.
\end{abstract}

\section{Keywords: Level of Nurse's Knowledge, Postextubation Dysphagia \& Practice}

\section{Introduction}

Post-extubation dysphagia (PED), which is defined as the inability to effectively transfer food and liquid from the mouth into the stomach, has been reported in 3\% to62\% of adult patients who undergo prolonged mechanical ventilation (Kim et al., 2015, Macht et al., 2011).

Endotracheal intubation is life-sustaining, but it may contribute to post-extubation swallowing dysfunction (PSD), delaying oral intake. In particular, patients with prolonged intubation, often defined as $\geq 48$ hours of intubation, were at greater risk of developing PSD. Moreover, as acute and intensive care has advanced, critically ill patients are increasingly intubated, regardless of their age. It is reasonable to assume that aging related changes, coupled with multiple comorbidities, are likely to change PSD (Tsai et al., 2016, Sassi et al., 2018).

Endotracheal tubes can cause dysphagia via mucosal abrasions, supraglottic edema, or decreased laryngeal sensation, whereas critical illness alone is thought to contribute to this disorder by damaging peripheral and bulbar nerves and muscles, altering cognition, and causing dysregulation of the swallowing reflex (Macht et al., 2012, Zuercher et al., 2019).

Translaryngeal intubation can affect the laryngeal structures as a result of direct impact during intubation, in the course of prolonged intubation, in restless patients, as a consequence of abrasion of the laryngeal mucosa, or secondary to the mere presence of the orotracheal tube (Carmona et al., 2016, Fernández-Carmona et al., 2012).

Dysphagia after prolonged orotracheal intubation is reported to increases a patient's risk for aspiration, leading to increased risk for morbidity and mortality. Identification of specific risk factors that may predispose a patient to post-extubation dysphagia and aspiration risk is important (Nizolek et al., 2014).

Moderate to severe postextubation dysphagia has also been associated with delayed return to oral eating need for feeding tube placement, pneumonia, higher reintubation rates, longer hospital stay, and higher mortality rates (Malandrak et al., 2016).

Early detection and initiation of proper interventions may diminish complications related to dysphagia and improve quality of referrals, health outcomes, and quality of life for individuals with dysphagia. In acute settings, nurses are available on a 24-hour basis, and may distinguish individuals with dysphagia and begin interventions that may prevent further complications until speech-language pathologist (SLP) can perform a formal assessment (Dondorf et al., 2016, McGinnis et al., 2019). 
Collaborate with physician and dietitian regarding a nutritional assessment and nutritional plan to ensure that the patient receiving enough nutrition, Provide patient with single-textured soft food (e.g., cream cereal) that maintain their shape because these foods require minimal oral manipulation and collaborate with physician and pharmacist regarding oral medication administration to adjust medication regimen to prevent aspiration and chocking and to ensure all prescribed medications are swallowed (Urden et al., 2017, Urden et al., 2013).

Nurses, technicians, and nursing assistants have an important role in the care of patients with postextubation dysphagia, as they are the professionals that are present bedside twenty four hours per day, and especially at mealtimes. These professionals may observe the signs and symptoms of dysphagia and through the identification, assessment, and early establishment of nursing interventions, they can help in the treatment and prevention of complications associated with this condition (Albini et al., 2013).

\section{Significance of the study}

It has been observed, from my experience in intensive care units, that post-extubation dysphagia is potentially life-threatening with consequences such as malnutrition, dehydration, aspiration pneumonia, and increased risk of complication, discharge to nursing home and higher mortality. Therefore, nurses should have knowledge and good practice in dealing with these challenges. Hence the significant of this study will appear in a clear need for assessing the nurses' knowledge and practice regarding dysphagia patient care. The second significant of this study, it will be the first study in Assiut university.

The aim of the study

The aim of this study was to assessment of nurses' knowledge and practice regarding patients with postextubation dysphagia in trauma intensive care unit.

\section{Research questions}

1. What is the level of knowledge of nurses regarding concept, phase, causes, complications, management, risk factors, complications, signs and symptoms of postextubation dysphagia?

2. What is the total level of knowledge and practice about postextubation dysphagia?

3. Is there a correlation between total level knowledge and practice?

Subjects and Methods

Research design:

Descriptive design was used in the study.

\section{Setting of the study}

The study was conducted in trauma intensive care unit of Assuit university hospital.

\section{Sampling}

A convenience sample of 50 nurses' working in trauma intensive care unit.

Inclusion criteria

1. Age nurses' 20 years or older

2. Nurses with bachelor degree

3. Diploma in nursing and Technical nursing

4. Nurses have experience in intensive care units at least one year

\section{Exclusion criteria}

Nurses' who experience in intensive care units at less than one year.

Study tools:

Three tools were developed or adopted by the researcher, tested for validity piloted for reliability, and utilized to collect data pertinent to the study.

Tool I: Self-administered questionnaire sheet:

Arabic interview questionnaire sheet was developed by researcher based on reviewing related literatures. The overall purpose of this questionnaire was to assess the nurse's knowledge and practice about postextubation dysphagia. It was developed and translated into Arabic language and it consists of two parts:

Part (1): Socio-demographic characteristics of nurses:

It includes: age, gender, qualification, years of experience and previous training course.

Part (2): assessment of nurses' knowledge: This part covered the following information's:

Nurse's knowledge about postextubation dysphagia: it includes 8 questions;

* Phases, concept, causes, and complications of postextubation dysphagia include (23) items.

* Factors that increases the risk for postextubation dysphagia in ICU include (5) items.

* Diseases that cause postextubation dysphagia include (7) items.

* Position that keep the patient during and after feeding include (4) items.

* Assessment patients' during giving oral care hygiene include (4) items.

* Experience specific problems when providing oral hygiene care include (5) items.

* Management of postextubation dysphagia include (5) items.

* The nurse has identified postextubation dysphagia include (3) items.

* Knowledge nurses' with trauma disorders .It was include (8) questions.

\section{Scoring system}

A scoring system for knowledge was developed based on clearly defined number of points (Albini et al., 2013). 
Total knowledge score (53) was classified as follows

Low knowledge $<50 \%$

- Moderate knowledge 50-74\%

High knowledge $>75 \%$

Tool II: Observation checklist sheet

An observational checklist has been developed by the researcher based on reviewing related literatures and according to modification was done. The overall purpose of this observation checklist was to assess the nurse's performance for patient postextubation dysphagia in ICU. It included (53) items:

* Screening Oral care procedure included (10) items.

* $\square \square$ Tools for evaluation postextubation dysphagia in ICU included (10) items.

* Assess risk factor for postextubation dysphagia in ICU included (6) items.

* Oral assessment "BRUSHED" assessment model included (7) items.

* Equipment oral care included (4) items.

* Measurement used in the passage of NG tube.

* Tests you used to check the correct positioning of NG tube included (4) items.

* Prevention of aspiration during hand and tube feeding included (8) items.

* Maneuvers to decrease aspiration risk in postextubation patients included (3) items.

Scoring system

A scoring system for performance was developed based on clearly defined number of points.

Total performance score (53) was classified as follows;

- Low practice $<50 \%$

- Moderate practice $50-74 \%$

- High practice $>75 \%$

\section{Methods}

The current study was carried out on two phases, involves the preparatory phase, implementation phase.

Preparatory phase $\left(1^{\text {st }}\right.$ phase $)$

1. Preparation of tools for data collection was done during this phase.

2. An official permission to proceed with the proposed study was obtained from the head of the trauma care unit department as well as the hospital nursing director after explaining the aim and nature of the study.

3. The tools used in this study were developed by the researcher based on reviewing the relevant literature.

4. Confidentiality and anonymity was assured.

5. Content validity: The tools were tested for content related validity by jury of 2 specialists in the field of critical care nursing from
Assiut- University, and the necessary modifications were done.

Implementation phase ( $2^{\text {nd }}$ Phase)

1. Permission was obtained from administration of hospital through written letter from my college.

2. Explain the aim and contents of the study to nursing supervisors and physicians to gain their cooperation and allow the release of nurses attend to teaching sessions during minimal workload activities.

3. Data was collected at trauma intensive care unit over a period of 7 months from March 2017 till October 2017.

4. At initial interview the researcher was introduce herself to initiate line of communication.

5. Self-questionnaire sheet filled by nurse's tool I ( $1^{\text {st }}$ and $2^{\text {nd }}$ Parts).

6. An observational checklist was carried out during nurses giving care for postextubation dysphagia patient the researcher observed nurses performance in the morning and the afternoon shift each observation lasted for 20 minutes by using the direct observation technique (tool II).

\section{Pilot study}

A pilot study was conducted on $10 \%$ of sample 5nursesthe feasibility and applicability of the tools. Reliability Statistics for nurses knowledge assessment questionnaire done by Cronbach's $\operatorname{Alpha}(\mathrm{R}=.886)$. Also, reliability Statistics for observation checklist sheet done by Cronbach's Alpha( $\mathrm{R}=.928)$.

\section{Ethical considerations}

Oral permission for voluntary participation was obtained from patient and nurses. The purpose, steps and benefits of study was explained to nurses and patient. After that obtaining a verbal consent by nurses and subject to participate in the study, and reassuring him about the strict confidentiality of any obtained information, and that the study results would be used only for the purpose of research.

\section{Statistical analysis}

Data entry was done using compatible personal computer by the investigator. The statistical analysis was done using SPSS-21 statistical software package and excel for figures. The content of each tool was analyzed, categorized and then coded by the investigator. Data were form of frequencies and percentages for qualitative variable. Pearson-moment product correlation coefficient was used to find out the relationship between total knowledge and practice 


\section{Results}

Table (1) Percentage distribution of studied critical care nurses according to their socio-demographic characteristics $($ No. $=\mathbf{5 0})$

\begin{tabular}{|l|c|c|}
\hline \multicolumn{1}{|c|}{ Socio-demographic characteristics } & No & \% \\
\hline Age group & & 32.0 \\
\hline Less than 25 years & 16 & 28.0 \\
\hline 25-30 years & 14 & 40.0 \\
\hline More than30 years & 20 & \\
\hline \multicolumn{1}{|c|}{ Mean +SD } & \multicolumn{2}{|c|}{$29.03 \pm 7.49$} \\
\hline Experience years & 8 & 16.0 \\
\hline One year & 6 & 12.0 \\
\hline 1-3 year & 9 & 18.0 \\
\hline 3-5 year & 27 & 54.0 \\
\hline Over 5 years & \multicolumn{2}{|c|}{} \\
\hline Educational qualification & 26 & 52.0 \\
\hline Diploma nursing & 8 & 16.0 \\
\hline Technical nurse & 16 & 32.0 \\
\hline Bachelor & & 72.0 \\
\hline Training courses & 36 & 28.0 \\
\hline NO & 14 & \\
\hline Yes & \multicolumn{2}{|c|}{} \\
\hline
\end{tabular}

Table (2): Overall knowledge of Postextubation dysphagia among nurses' working in trauma ICU (n=50)

\begin{tabular}{|l|c|c|c|}
\hline \multicolumn{1}{|c|}{ Variable } & \multirow{2}{*}{$\begin{array}{c}\text { Total score } \\
\text { n }\end{array}$} & \multicolumn{2}{c|}{ Trauma ICU(NO.=50) } \\
\cline { 3 - 4 } & & Achieved points & $\begin{array}{c}\text { Level of } \\
\text { Knowledge }\end{array}$ \\
\hline Phases of swallowing & $1(100 \%)$ & $0.33(33.33 \%)$ & Low \\
\hline Concept of Postextubation dysphagia & $1(100 \%)$ & $0.63(63.33 \%)$ & Moderate \\
\hline Causes of postextubation dysphagia & $1(100 \%)$ & $0.13(13.33 \%)$ & Low \\
\hline Complication of Postextubation dysphagia & $9(100 \%)$ & $5.23(58.15 \%)$ & Moderate \\
\hline Risk factors Postextubation dysphagia & $5(100 \%)$ & $1.6(32 \%)$ & Low \\
\hline $\begin{array}{l}\text { Signs and symptoms of Postextubation } \\
\text { dysphagia }\end{array}$ & $9(100 \%)$ & $5.5(61.11 \%)$ & Moderate \\
\hline Diseases causes postextubation dysphagia & $7(100 \%)$ & $1.27(18.1 \%)$ & Low \\
\hline Assessment of patient for providing oral hygiene & $4(100 \%)$ & $0.88(88 \%)$ & High \\
\hline Problems with oral hygiene with postextubation & $5(100 \%)$ & $0.53(53 \%)$ & Moderate \\
\hline $\begin{array}{l}\text { Management of patient with } \\
\text { dysphagia }\end{array}$ & $5(100 \%)$ & $1.13(28.33 \%)$ & Low \\
\hline Long release medication orally & $1(100 \%)$ & $1.17(23.33 \%)$ & Low \\
\hline $\begin{array}{l}\text { The mechanism of swallowing are controlled by } \\
\text { brain }\end{array}$ & $1(100 \%)$ & $0.47(46.67 \%)$ & Low \\
\hline $\begin{array}{l}\text { Is postextubation dysphagia causes aspiration } \\
\text { pneumonia? }\end{array}$ & $1(100 \%)$ & $0.83(83.33 \%)$ & High \\
\hline $\begin{array}{l}\text { Change in the voice is potential sign of } \\
\text { postextubation dysphagia? }\end{array}$ & $1(100 \%)$ & $0.47(46.67 \%)$ & Low \\
\hline $\begin{array}{l}\text { Trauma patients may be accompanied by } \\
\text { postextubation dysphagia? }\end{array}$ & $1(100 \%)$ & $0.33(33.33 \%)$ & Low \\
\hline $\begin{array}{l}\text { Coughing is potential evidence of postextubation } \\
\text { dysphagia? }\end{array}$ & $1(100 \%)$ & $0.77(76.67 \%)$ & High \\
\hline Total of overall knowledge & $\mathbf{5 3 ( 1 0 0 \% )}$ & $\mathbf{2 4 . 4 ( 4 5 . 1 8 \% )}$ & Low \\
\hline
\end{tabular}




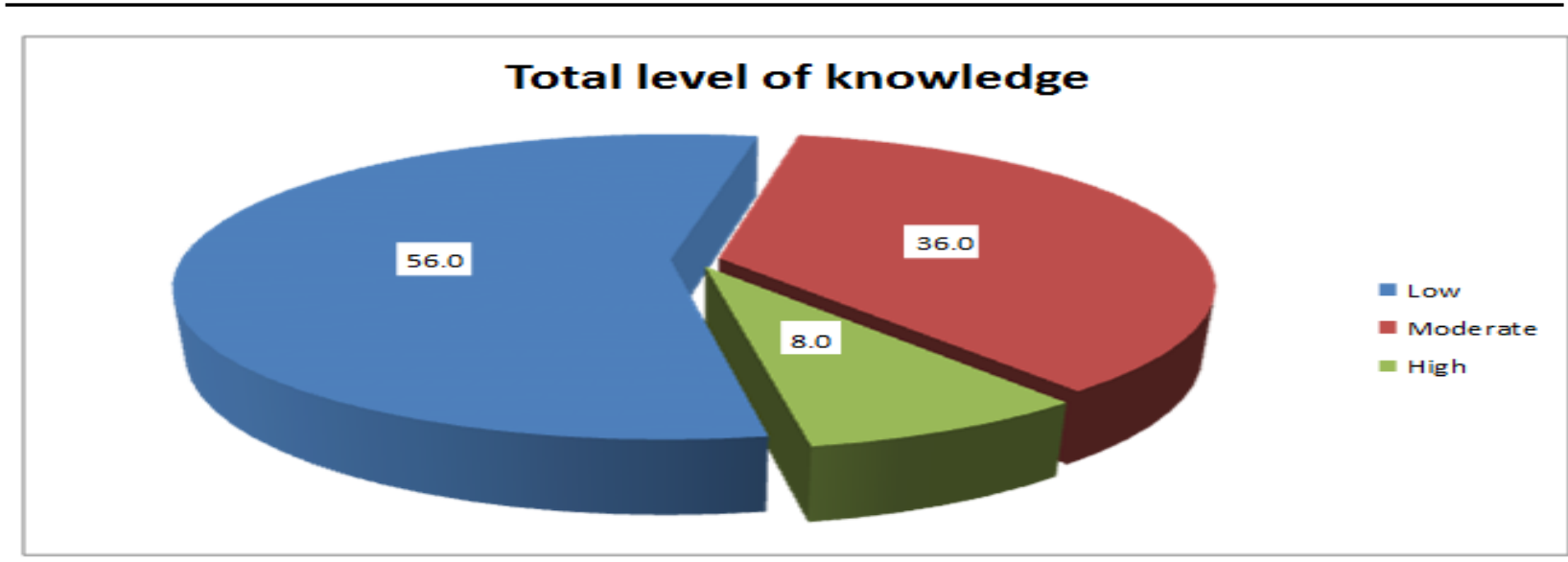

Figure (1): total level of knowledge among nurses' working in the trauma ICU ( $n=50)$

Table (3): Overall practice of postextubation dysphagia among nurses' working in trauma ICU (n=50)

\begin{tabular}{|l|c|c|c|}
\hline \multicolumn{1}{|c|}{ Variable } & \multirow{2}{*}{ Total score } & \multicolumn{2}{c|}{ Trauma ICU(NO.=50) } \\
\cline { 3 - 4 } & Achieved points & Level of Practice \\
\hline $\begin{array}{l}\text { Typically clinical evaluation for post- } \\
\text { estuation dysphagia(PED) }\end{array}$ & $10(100 \%)$ & $3(30 \%)$ & Low \\
\hline $\begin{array}{l}\text { Assess risk factors for post-estuation } \\
\text { dysphagia }\end{array}$ & $6(100 \%)$ & $1.7(28.33 \%)$ & Low \\
\hline $\begin{array}{l}\text { Oral assessment BRUSHED } \\
\text { assessment model }\end{array}$ & $7(100 \%)$ & $2.13(30.48 \%)$ & Low \\
\hline Equipment oral care & $4(100 \%)$ & $2.13(53.33 \%)$ & Moderate \\
\hline Oral care procedure & $10(100 \%)$ & $4.2(42 \%)$ & Low \\
\hline $\begin{array}{l}\text { Measurement used in the passage of } \\
\text { NG tube }\end{array}$ & $1(100 \%)$ & $0.8(80 \%)$ & High \\
\hline $\begin{array}{l}\text { Test you used to check the correct } \\
\text { positioning of NG tube }\end{array}$ & $4(100 \%)$ & $2.27(56.67 \%)$ & Moderate \\
\hline $\begin{array}{l}\text { prevention of aspiration during hand } \\
\text { and tube feeding }\end{array}$ & $8(100 \%)$ & $3.03(37.92 \%)$ & Low \\
\hline $\begin{array}{l}\text { Evaluated maneuvers to decrease } \\
\text { aspiration risk in postextubation } \\
\text { patients }\end{array}$ & $3(100 \%)$ & $0.97(32.22 \%)$ & Low \\
\hline Total of overall practice & $\mathbf{5 3 ( 1 0 0 \% )}$ & $\mathbf{2 0 . 2 3 ( 3 8 . 1 6 \% )}$ & Low \\
\hline
\end{tabular}

\section{Total level of practice}

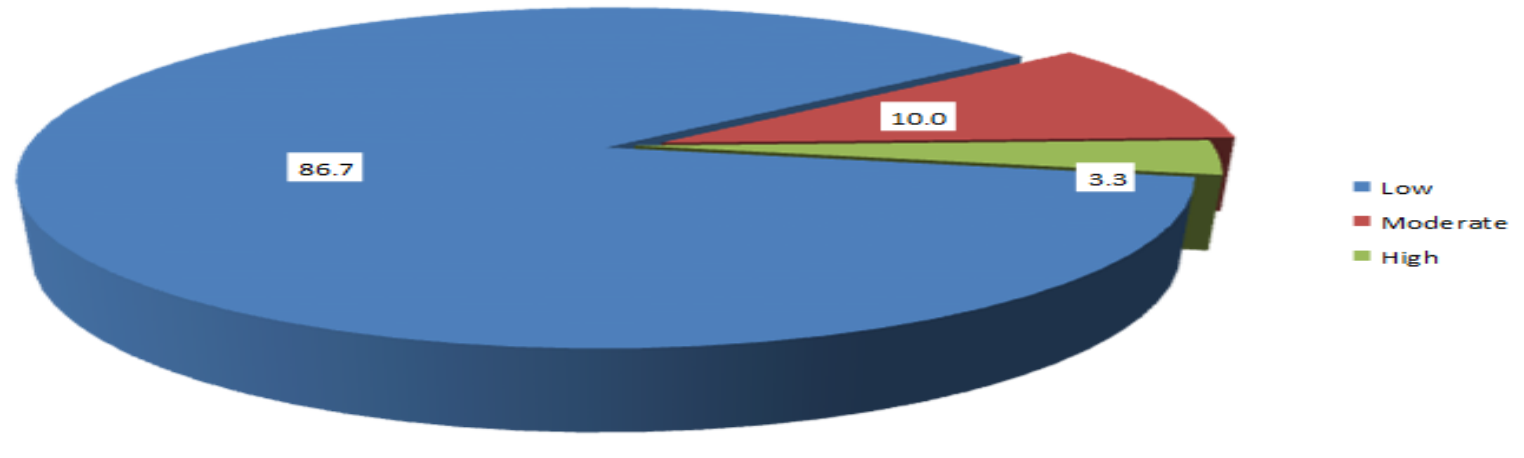

Figure (2): Total level of practice among nurses' working in the trauma ICU $(n=50)$ 


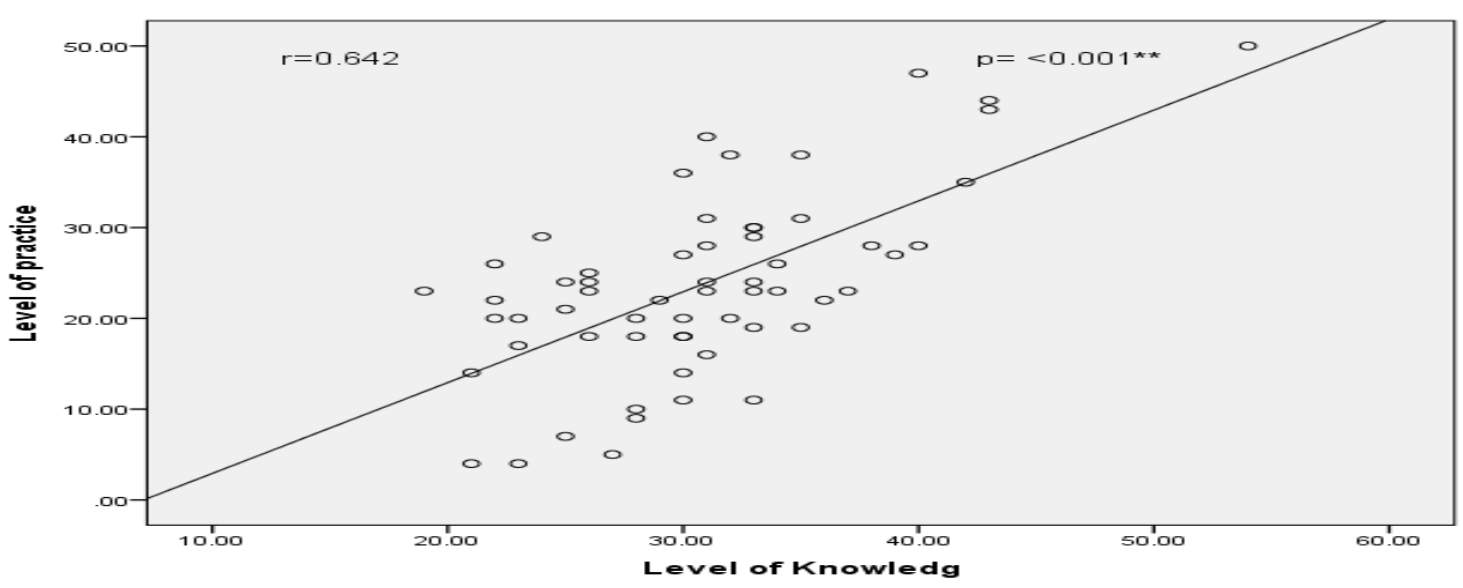

Figure (3): correlation between total nurses' knowledge and practice

Table (1): Show that, the studied sample consists of 50 nurses from trauma ICU.As regard to age; the majority of nurses' $(40 \%)$ were more than 30 years with Mean \pm SD $(29.03 \pm 7.49)$.

Regarding nurses' educational qualification, the majority nurses $(52 \%)$ had diploma nursing.Regard to experience years, the majority of nurses had over 5 years of experience. Concerning to previous training courses, the majority (72\%) of nurses' in trauma ICU had not received on the job training.

Table (2): This table shows that the correct response rate for all nine practice subsections (typically clinical evaluation for post-estuation risk factors, an oral assessment....), combined was $(38.16 \%)$ in trauma ICU this result in an average of (20.23) points in , out of 53 points

which could be achieved. This demonstrates a low overall practice level

in

nurse's trauma ICU

Figure (1): This figure shows that, the majority $(56.0 \%)$ of the nurses had low knowledge.

Table (3): This table shows that the correct response rate for all seventeen knowledge sub-sections (phases, concept, causes, complication, risk factors, signs and symptoms...) combined was $(45.18 \%)$ in trauma ICU this result in an average of (24.4)points trauma ICU, out of 54 points which could be achieved. This demonstrates a low overall knowledge level in nurse's trauma ICU.

Figure (2): this figure shows that, the majority $(86.7 \%)$ of the nurses had low knowledge.

Figure (3): show that there was a significant positive correlation between score of knowledge and score of practice ( $\mathrm{p}$. value $=0.001)$.

\section{Discussion}

Results of this study indicated that nurses' do not have adequate knowledge and practice of dysphagia; sample of this study was consisted of nurses who are working in trauma ICU. It is more common to see patients with allowing difficulties in these intensive care units.

The aim of this study was to assessment of nurses' knowledge and practice about postextubation dysphagia patients in trauma intensive care unit.

In current study, all of participants were female. This attributes to the university education between females more than males in Egypt. The result was in agreement with other study conducted in a University Hospital located in Assuit, Egypt by Al-Qadi, (2015) who reported that, all of participants of his studied were females.

The result of the present study revealed that, nearly half of participants had nursing diploma. These findings consistent with a study performed by Rhoda, (2015) who reported that, the majority of participants, in his study, had nursing diploma.

Concerning to previous training courses, the current study presented the majority of participants said they had not received on the job training. These results were in disagreement with other study conducted in Brazil by Albini et al., (2013) who reported in his studied that, the majority of participants had received on-the-job training.

The identification of swallowing disorders may help detect patients at high risk of aspiration, preventing pulmonary complications, such as aspiration pneumonia. The aspirations may be mildly symptomatic, requiring the active assessment of swallowing in these patients, especially the remaining intubated for more than 48 hours (Weber Werle et al., 2016).

The results of current study demonstrated that, the overall correct average response rate for knowledge complication of postextubation dysphagia was fifty eight percent, this demonstrate a moderate knowledge in trauma ICU This finding agrees with (Abu- 
snieneh \& Saleh, 2017) conducted a study to the level of Jordanian nurse's knowledge about dysphagia, the result showed that nurses' had a moderate knowledge complication of dysphagia

The incidence of PED is increased in the presence of risk factors that cause laryngeal irritation and inflammation, including prolonged mechanical ventilation $(>50 \%$ of patients with PED were intubated for $>48$ hours), the presence of tracheostomy, nasogastric tubes, or a recent tranceslophageal echocardiography study. A largebore nasogastric tube is more likely than a small-bore nasogastric tube to be associated with the development of PED (Rassameehiran et al., 2015).

The results of current study demonstrated that, the overall correct average response rate for knowledge risk factors of postextubation dysphagia was thirty two percent ,this demonstrate a low knowledge in trauma ICU. From the researcher's point of view, this lack of knowledge regarding risk factors of postextubation dysphagia may be the lack of educational and training programs about risk factors of postextubation dysphagia.

Regarding to level of knowledge, the findings show that the nurses have a low level of overall knowledge in trauma ICU. An explanation for this low level in trauma ICU could be that, nurses' in trauma ICU has more contact with trauma patients after extubation. There are also three possible reasons to explain the low level of overall knowledge.

First, their formal education background and training experience may be a factor related to this low level. The majority of participants in current studied graduated with a diploma and technical nursing. The content included in both these curriculums was not specifically focused on up- to-date information about postextubation dysphagia. In addition, the most of nurses were not trained in postextubation dysphagia training program.

Second, it has been proposed that the greater the working experience the higher the knowledge gained. However, the additional analysis did not support this proposition. There were no significant differences in nurses' knowledge with different working experiences. It was found that nurses with more years of working experience (over 5 years) had lower levels of knowledge than those with less years of working experience (1-3 years). This may be because nurses with more years of working experiences may have had less chance to gain access to up to-date information about dysphagia. It was found that nurses with many years of clinical experience (less 5 years) had high levels of knowledge regarding dysphagia and its associated care due to their not up-dating their knowledge.
Third, the lack of learning resources for nurses to update their knowledge would be another reason for this low level of knowledge. In Assuit university hospital, there is a lack of learning resources for nurses to update their knowledge. Nursing journals are not available even at hospitals. These facts indicate that nurses still have an inadequate knowledge in trauma ICU due to their knowledge not being up-to-date either by lack of formal training or reading text books or journals.

Regarding to level of practice, the findings show that, the nurses had low level of overall practice regarding to dysphagia in both units. A possible reason for explaining this low level of practice may be due to certain factors

First, the shortage of nursing staff and the limited working time available for direct patient care in preventing dysphagia may be an organizational factor related to the low level of practice.

Second, education and training, administrative support, and the provision of guidelines are particularly essential for nurses to prevent the development of postextubation dysphagia. In this study hospital, no in-service education or training or provisions of guidelines are available for preventing dysphagia development.

\section{Conclusions}

The study concluded that, the overall knowledge of participants was found to be low knowledge. Regarding the overall practice of nurses' was found to be low practice.

The results of the present study show that participants have moderate knowledge regarding the signs and symptom, complications, and concept of postextubation dysphagia, but poor knowledge about phases, causes, risk factors and management of postextubation dysphagia.

\section{Recommendations}

Based on the results of the current study, the following recommendations are suggested:-

- Training program about postextubation of dysphagia should be in developed and implemented for nurses.

- An information booklet about postextubation dysphagia in trauma patients aimed at nurses and health professionals should be developed and implemented on trauma intensive care unit where the nurses are most likely to deal with postextubation dysphagia. The booklet should contain information about postextubation dysphagia, the concept, phases, signs and symptoms, risk factors, possible complication and how to manage postextubation dysphagia patients. 
- A guideline for nurses should be developed and implemented at all hospitals. This will encourage the nurses to ensure that each trauma patient receives the correct treatment for postextubation dysphagia from the time of admission.

\section{References}

1. Abu-snieneh, H., \& Saleh, M., (2017): The level of jordanian nurse's knowledge about dysphagia: descriptive study. International Journal of Applied and Natural Sciences (IJANS), 6(6).

2. Al-Qad, A., (2015): Impact of Educational Training Program on Nurse's Performance for Patient Undergoing Endotracheal Tube at Assiut University Hospital Thesis.

3. Albini, R., Soares, V., Wolf, A., \& Goncalves, C., (2013): Knowledge of nursing professionals about the care to dysphagic patients in intensive care units. Revista CEFAC, 15(6), 1512-1524.

4. Brodsky, M., Huang, M., Shanholtz, C., Mendez-Tellez, P., Palmer, J., Colantuoni, E., \& Needham, D., (2017): Recovery of Dysphagia Symptoms after Oral Endotracheal Intubation in ARDS Survivors: A 5-Year Longitudinal Study. Ann Am Thorac Soc, 14(3), 376-383.

5. Dondorf, K., Fabus, R., \& Ghassemi, A., (2016): The interprofessional collaboration between nurses and speech-language pathologists working with patients diagnosed with dysphagia in skilled nursing facilities. $\mathbf{J}$ Nurs Educ Pract, 6(4), 17-20.

6. Esquinas, A., (2016): Noninvasive Mechanical Ventilation and Difficult Weaning in Critical Care: Key Topics and Practical Approaches: Springer.

7. Fernández-Carmona, A., Peñas-Maldonado, L., Yuste-Osorio, E., \& Díaz-Redondo, A., (2012). Exploration and approach to artificial airway dysphagia. Medicina Intensiva (English Edition), 36(6), 423-433.

8. Khoja, M., (2018): Registered nurses' knowledge and care practices regarding patients with dysphagia in Saudi Arabia. International journal of health care quality assurance.

9. Macht, M., Wimbish, T., Clark, B., Benson, A., Burnham, E., Williams, A., \& Moss, M., (2011): Postextubation dysphagia is persistent and associated with poor outcomes in survivors of critical illness. Critical care, 15(5), R231.

10. Malandraki, G., Markaki, V., Georgopoulos, V., Psychogios, L., \& Nanas, S., (2016): Postextubation dysphagia in critical patients: a first report from the largest step- down intensive care unit in Greece. American journal of speech-language pathology, 25(2), 150-156.

11. McGinnis, C., Homan, K., Solomon, M., Taylor, J., Staebell, K., Erger, D., \& Raut, N., (2019): Dysphagia: interprofessional management, impact, and patient-centered care. Nutrition in Clinical Practice, 34(1), 8095.

12. Miller, J., (2017): Critical Care Nursing: Diagnosis and Management 8th edition,chapter 5. In: AACN.

13. Moraes, D., Sassi, F., Mangilli, L., Zilberstein, B., \& de Andrade, C., (2013): Clinical prognostic indicators of dysphagia following prolonged orotracheal intubation in ICU patients. Critical care, 17(5), R243.

14. Nizolek, K., (2014): Risk factors for dysphagia in critically-ill patients with prolonged orotracheal intubation. Columbia University,

15. Rassameehiran, S., Klomjit, S., Mankongpaisarnrung, C., \& Rakvit, A., (2015); Postextubation dysphagia. Paper presented at the Baylor University Medical Center Proceedings.

16. Rhoda, A., \& Pickel-Voight, A. (2015). Knowledge of nurses regarding dysphagia in patients post stroke in Namibia. curationis, $38(2)$.

17. Sassi, F., Medeiros, G., Zambon, L., Zilberstein, B., \& Andrade, C., (2018): Evaluation and classification of postextubation dysphagia in critically ill patients. Revista do Colegio Brasileiro de Cirurgioes, 45(3), e1687-e1687.

18. Urden, L., Stacy, K., \& Lough, M., (2013): Critical care nursing, diagnosis and management, 7: critical care nursing: Elsevier Health Sciences.

19. Weber Werle, R., Matias dos Santos Steidl, E., \& Bastos Pereira, M., (2016): Dysphagia in neurological patients after mechanical ventilation. International Journal of Current Research, 8(11), 41253-41256.

20. Wittekamp, B., van Mook, W., Tjan, D., Zwaveling, J., \& Bergmans, D., (2009): Clinical review: post-extubation laryngeal edema and extubation failure in critically ill adult patients. Critical care, 13(6), 233.

21.Zuercher, P., Moret, C., Dziewas, R., \& Schefold, J., (2019): Dysphagia in the intensive care unit: epidemiology, mechanisms, and clinical management. Critical care, 23(1), 103. 